\title{
AESTHETIC EDUCATION OF STUDENTS THROUGH PHYSICAL EDUCATION AND SPORTS
}

\author{
Xojametov Ajiniyaz Andriyanovich \\ Independent Researcher, Nukus State Pedagogical Institute, Nukus, Uzbekistan
}

Article DOI: https://doi.org/10.36713/epra7990

DOI No: 10.36713/epra7990

\begin{abstract}
The article describes one of the most important conditions for the formation of civil society today that is importance of educating a highly spiritual, well-rounded young generation. This article discusses actual issues and the formation of a high-spirited, morally and aesthetically educated generation, as well as scientific study of the importance of aesthetic education in the process of reforming and modernizing society. While the aesthetic form of upbringing is involved in social processes, in turn, it considers its main goal to increase people's interest in positive work being done in society. Therefore, one of the ultimate goals of aesthetic education should be to enrich the spiritual world of a man. Aesthetic education not only encourages man to create innovations, but also teaches him to develop on the basis of the principles of sophistication, requirements of beauty. Accordingly, currently, main means of aesthetic education will include such areas as art, information technology, nature, labor, physical education and sports. Furthermore, in this article, the peculiarities of the development of women's sports, the implementation of state programs, promotion of healthy lifestyles, strengthening reproductive health of the population, involvement of women in sports, creating the necessary conditions for their regular participation in popular sports are mentioned.
\end{abstract}

KEY WORDS: aesthetic education, Physical education, sports, women, all means of aesthetic education, labor, sports aesthetics.

\section{INTRODUCTION}

Currently, one of the most important conditions for the formation of civil society is upbringing of a highly spiritual, harmoniously developed, young generation. The formation of a highly spiritual, morally and aesthetically educated generation and scientific study of the importance of aesthetic education in the process of reforming as well as modernizing society remains one of the most actual problems of the time. The aesthetic form of upbringing is involved in social processes. The aesthetic form of upbringing, in turn, considers its main goal to make people enjoy positive works that are being done in society, and to increase a sense of interest in democratic relations. Therefore, the ultimate goal of aesthetic education should be to enrich the spiritual world of a man.

Moreover, aesthetic education encourages man not only to create innovations, but also teaches him to develop on the basis of the principles of sophistication, the requirements of beauty. After all, a person in the world will not be born with rich aesthetic outlook, feelings and taste. In this case, these skills are formed as a result of observing, studying, and making appropriate conclusions and learning from life. Under the influence of these feelings, a man discovers a world that is completely new to him. Therefore, it is self-evident that a person who deeply understands this necessity cannot be indifferent not to join the social development of society.

\section{LITERATURE REVIEW}

All means of aesthetic education are educational activities that serve to develop the aesthetic attitude of students to reality. Aesthetic education has its own power of influence. Without aesthetic education, the scope of human knowledge cannot be created and developed. It is also an important task of aesthetic education techniques to develop the human ability to think artistically. Thus, aesthetic education tools are distinguished by two distinct features. First, they convey information about events that take place in reality to a person in an understandable way. Secondly, it is noteworthy that modern science delivers aesthetic perception of 
aesthetic features based on active experiences. Accordingly, the main means of aesthetic education can include such areas as: art, information technology, nature, labor, physical education and sports $[2,27]$.

Currently, the scope of aesthetic education is expanding. Furthermore, aesthetic education sets the following important tasks:

- Improving people's ability not only to actively master the works of art, literary activities, but also to understand and appreciate their aesthetic nature;

- Demonstrate creative potential of members of society, and inspire confidence in their ability to use them;

- To develop the ability to have a pure attitude to the social processes of nature and society, and to work diligently for their development;

- To increase respect for our spiritual heritage of the past, to create a basis for the formation of feelings of national pride;

- To develop all forms of creativity, to face the world, and to encourage them to promote those aspects that are beneficial to the interests of the nation.

Labor is a purposeful activity performed by a person with mental or physical strength. Labor is a means of improving the daily spiritual and material well-being of human life, the creation of spiritual and material values. In labor, young people are brought up both mentally and physically, and grow spiritually. However, where labor has become a heavy obligation, these features of labor might be lost.

Therefore, in order for labor to be highly productive in all respects, it must be free, and the labor process must be creative and interesting. In the aesthetic upbringing of the individual, the role of the education system is vitally important. Labor is an important factor in the aesthetics of life. There are modern forms of shaping the beauty of behavior in young people, taste and ingenuity are considered a sign of high culture, and ignorance is accounted for a defect in the development of a man's personality. Young people might have a problem with the balance of natural beauty and aesthetic taste, they include: politeness and humiliation. There is an aesthetic culture of the individual and society, and the influence of the socio-spiritual life of society on the formation of aesthetic culture is great. The aesthetic culture of the individual and society is inextricably connected. There are national and universal aspects of increasing aesthetic culture, and the positive and negative impact of "popular culture" on aesthetic taste is large.

Aesthetic development, on the other hand, is dialectically related to aesthetic need and aesthetic taste. There are also spiritual and aesthetic aspects of sports, and we can see that the impact of sports on the beautification of the human body and lifestyle, modern importance of sports aesthetics is incomparable. Also, with the change of time, a man's attitude to the society and nature may change. This is undoubtedly a process related to human thinking. Undoubtedly, this is a process related to human thinking. After all, there is no process that involves human relationships unless there is contemplation involved. Therefore, it is no coincidence, that the influence of people's thinking and worldview on reality is recognized as a condition for the formation of a national idea and national ideology, which is currently considered as the most actual problem. In these processes, aesthetics manifests itself in practice through aesthetic education.

After all, as we have mentioned earlier, aesthetic education helps a person to enjoy the beauties of life and art, to appreciate them, and to form feelings of creating beauty itself. However, this process is not spontaneous, but involves a number of factors and tools.

\section{METHODOLOGY}

Sports aesthetics studies the aesthetic laws of sports, studies the aesthetic content of sports, its place in the culture of society, the relationship between sports and art, as well as analyzes the spiritual and aesthetic aspects of human physical development. It is known for us that although sports and physical education are almost always mentioned together, they differ significantly from each other. Physical education consists mainly of exercises, or sets of exercises, of a mass nature, in which all sections of society at all ages, voluntarily engaged in "for their health", and it is directed to the maintenance of human health. Sport, on the other hand, involves the individual or group competition of specially trained people, mostly young people, under the supervision of specialist coaches, regardless of their field. Physical training, regardless of its form (individual, collective), rejects competition, and allows a person to choose from a variety of exercise forms. However, in sports, competition comes first, and certain exercises are mandatory.

However, this obligation allows the athlete to move freely within a particular type of sport, that is a creative approach in the sport is not prohibited but supported. For example, in rhythmic gymnastics competitions, each athlete performs the exercise of her choice, accompanied by music of her choice, but does not deviate from the rules of this sport. Thus, it is not possible to add physical education to sports, or to replace them. In most other forms of sports, all athletes do the same exercise, but what sets them apart, keeps the spirit of the competition, and doesn't extinguish it, is the creative, unique approach that each athlete performs the same exercise. At the same 
time, it requires the athlete to dominate the body of his member, to present this dominance to the spectator in the form of flexible beauty, dexterity, glorious behavior. Therefore, sport is notable as a demonstration of the beauty of the human body.

The ancient Greeks approached sports from such a point of view centuries ago. However, unfortunately, the factor of competition later pushed beauty aside and turned it into a passion for the game, a peculiar form of gambling, valued by victory and defeat (gladiatorial betting in ancient Rome, later betting on horse racing) [2, 49]. We assume that the ancient Greek philosophers emphasized the aesthetic nature of the game, equating it with art. On the other hand, we think that Schiller considered artistic activity to be the highest form of play. Sport is first and foremost a game. A man enjoys sports in two ways: as a player-athlete and as a spectator-supporter. In sports, the spectator harmonizes with the athlete as if perceiving art, joining his behavioral movements, feeling that he is not an athlete, that is, an aesthetic distance.

In this regard, B. Lowe writes in his book "The Beauty of Sports", quotation stated by F. Kinon: "Theater is a type of art that develops based on the audience". In sports competitions, spectators behave as if they were watching a play: they applaud the high skilled masters, and do not hide their negative attitude towards those who perform poorly. In both sports and theater, we talk about the "game".

In addition to this, B. Lowe draws attention to the following lines from H. Slucher's book, "Sport and Existence": "Sport as a real sport, it can achieve aesthetic quality and elegance. Sport is a state of deep meaning for the athlete, sport requires courage, integrity and a high level of emotional enhancement, writes H. Slyusher about the aesthetic pleasure that an athlete feels" [5, 147]. When it comes to the peculiarities of sports aesthetics, sport is now recognized as a very widespread cultural field around the world. Especially, we can see this in the example of our country. Due to independence of the country, sports have become an integral part of national culture, competitions and friendly meetings in all its forms have turned into a tradition, and our national wrestling has gained the status of a universal sport, a special Ministry of Physical Culture and Sports has been established. Almost all of these positive changes have been done at the initiative and under the control of the head of our state. As a result, today, Uzbekistan is in the land of sports, became one of the countries exhibiting human physical beauty to the world.

\section{RESULTS AND DISCUSSION}

Among nations of the world, attention and love for mothers are paramount. In our national custom, respect for our mothers and wives has its own special characteristics in serving them. Everyone in the family, especially children, puts the mother's respect above all else. Especially, girls are taught to get married, start a family and always to be healthy, consequent, to become loyal to the family members. Most women respond well to such attention and respect, patiently justifying basic beliefs. "I will get married to a sniper who shoots the goal with a a bow, I will get married to a wrestler who fights honestly". Of course, these lines are familiar to all of us. Barchin, who fought for the Kalmiks in the epic "Alpamis", seems to have a sense in expressing the courage of Uzbek girls in this way. This is just an epic.

However, the courage and bravery of our women is a quality that has been preserved for thousands of years. It was not clear to us in those games of "five stones" and "rope jumping", however, positive effects of these games, which promote physical health in their movements, are important. During the years of independence of our country, great efforts have been made to restore national values, enrich the population spiritually and enlightenment. Not only among adults, but also among younger girls and schoolgirls, there are great changes in the acquisition of national pride and glory. The most exemplary and useful aspects of the Islamic world are being absorbed amongst women. On this basis, measures to create a healthy family, to raise children physically and spiritually harmoniously are expanding. Due to the independence, our female athletes often go abroad. Such processes serve to enrich our national culture. In particular, I. Tulaganova (Tennis), Y. Hamrokulova (Chess), S. Erkinbaeva (Judo), Z. Alieva (Karate), A. Keunimjaeva (Freestyle wrestling) and others are becoming stars of world sports. On the basis of the decrees and resolutions of the President of the Republic (from 1991 to the present) and several decisions of the Cabinet of Ministers of the Republic of Uzbekistan, measures are taken to ensure social and material security of women and their regular medical care.

It should be noted, that medical care is being provided on a regular basis to physically weak or sick women. The causes of physical infirmity and illnesses are more related to congenital or inadequate food intake. However, there are also a lot of overweight (overweight) women. In these two cases, compared to all drugs, the cases of being healthy as a result of exercise, various games (dances) have been scientifically and practically proven. For this reason, the use of exercise in the treatment of various diseases in central cities, and the number of healthcare centres and wellness facilities are increasing day by day. Recently, the number of women engaged in sportswear has increased significantly. These aspects were strictly limited by 
the mandatory nature of physical education classes, and the rules of sports competitions, but in recent years, as a result of national characteristics and traditions, use of appropriate clothing by our girls has been put into practice. These aspects are further refined without negating national characteristics.

It should be noted that TV shows, press releases, especially traveling abroad, business and other necessities, the results of the exchange of experience, the influence of new trends among young people in the areas of dressing, decorating, treatment has been increasing. Such aspects are especially evident in sports. In our country, the interest and activity of indigenous girls in sports schools and various communities is expanding. Along with men, like wrestling, oriental wrestling, kickboxing, football, and even weightlifting, sports are evolving. Such aspects serve to enhance reputation of the family, as well as the homeland. For this reason, parents are not inclined to allow their daughters to engage in sports such as gymnastics, swimming, athletics, volleyball, handball, tennis. Exercise, especially sports, is one of the most important factors in keeping women physically fit, healthy, active, and raising a healthy child. These aspects are increasingly being absorbed by all families, especially amongst young families. Nevertheless, in many older generations, as well as in some modern young families, negligence of physical and aesthetic upbringing of women is still strong. One of the main reasons for this is that by using customs as an excuse, men do not like women to do gymnastics and games in the morning or in their free time. In addition to this, most men and women are not familiar with the ways to use exercises, and are not well aware of educational aspects of exercises in improving health. For this reason, first of all, it is necessary to create appropriate conditions for women to exercise in the family and neighborhoods. Furthermore, it is necessary to develop and implement a set of special exercises for women, sports on simplified technical rules, taking into account national characteristics. Moreover, it is essential to organize lectures by specialist scientists, doctors, especially women, through television and radio.

\section{CONCLUSION}

Thus, women's committees should also work with sports organizations to create measures for the development of women's physical and aesthetic education. In general, in gymnastics and movement games, among women, training of staff with secondary special and higher education is a requirement of today's period [4, 69].

Consequently, it should be noted that the development of physical culture and aesthetic education amongst women, especially in the training of highly qualified specialists, is greatly influenced by the following women scientists and coaches: R.A. Qozieva (History of physical culture), O. Sobirova (Swimming), K.T. Rakhimjanova (Shokirjonova Athletics), G. Babdurasulova (Fencing, UzSWLU), R.A. Qosimova (Handball, Samarkand State University), J. Baymuratova and X. Baymuratova (Basketball, Nukus), Z. Alieva (Karate, Nukus Higher School of Sports), Z.N. Palvanova and D. Joldasbaeva (Rhythmic Gymnastics, Nukus Higher School of Sports). It is vitally important and essential to increase the number of such talented scientists and coaches in the future.

\section{REFERENCES}

1. Borev Y. Aesthetics. (In Russian language). Moscow, Gardariki, 2003.

2. Bichkov V.V. Aesthetics. (In Russian language). Moscow: Gardariki, 2004. pp. 27-49.

3. Abdulla Sher., B. Husanov. Aesthetics. Methodical manual. (In Uzbek language). Second edition. 2010.

4. Umarov E. Fundamentals of Aesthetics. (In Uzbek language). T. Sharq, 2012. pp. 69.

5. Lou B. Beauty of sport. (In Russian language). M., Raduga, 1984. pp. 147. 